\title{
Retinal Nerve Fiber Layer Thickness and Its Relationship With Executive Functions in Adult Attention Deficit Hyperactivity Disorder Patients
}

\author{
Derya Kaymak ${ }^{1}$ i ibrahim Gündoğmuş² ${ }^{\boxplus}$, Mihriban Dalkıran ${ }^{3}$, \\ Murat Küçükevcilioğlu ${ }^{4}$, and Özcan Uzun ${ }^{5}$ \\ ${ }^{1}$ Department of Psychiatry, Ankara Training and Research Hospital, Ankara, Turkey \\ ${ }^{2}$ Department of Psychiatry, Kırıkkale Yüksek İhtisas Hospital, Kırıkkale, Turkey \\ ${ }^{3}$ Department of Psychiatry, Health Science University Şişli Etfal Training and Research Hospital, İstanbul, Turkey \\ ${ }^{4}$ Department of Ophtalmology, Health Science University Gülhane Training and Research Hospital, Ankara, Turkey \\ ${ }^{5}$ Department of Psychiatry, Health Science University Gülhane Training and Research Hospital, Ankara, Turkey
}

Objective The aim of this study was to compare the thickness of the retinal nerve fiber layer (RNFL) with controls in individuals with attention deficit hyperactivity disorder (ADHD) and to examine the relationship between RNFL thickness and the level of performance in disease severity and executive function tests in ADHD cases.

Methods The study included 38 volunteer patients diagnosed with ADHD and 30 healthy volunteers. Adult ADHD self-report scale was used for ADHD symptom severity. Executive functions were evaluated by Digit Span Test, Verbal Fluency Test, Stroop Test, and Trail Making Test. RNFL thickness of all participants was evaluated using optical coherence tomography (OCT).

Results In the comparison of RNFL values, it was found that right mean, right temporal, right temporal inferior, left mean, left nasal, and left nasal inferior quadrant values were statistically thinner in ADHD cases compared to the control group ( $\mathrm{p}<0.05)$. There was no statistically significant correlation between the mean RNFL thickness values of the right and left eyes of ADHD cases and the symptom severity and performance levels in executive function tests.

Conclusion This study is a guide in terms of being the first study investigating the relationship between RNFL thickness, symptom severity, and various neuropsychological tests in adults with ADHD.

Psychiatry Investig 2021;18(12):1171-1179

Keywords Attention deficit hyperactivity disorder; Retinal nerve fiber layer; Optical coherence tomography; Executive functions.

\section{INTRODUCTION}

Attention deficit hyperactivity disorder (ADHD) is a neurodevelopmental disorder that starts in childhood and continues in adulthood at a rate of $40 \%-60 \%$, characterized by short attention span, distractibility, hyperactivity, and impulsivity, negatively affecting functionality. ${ }^{1,2}$ Although the underlying etiology of $\mathrm{ADHD}$ is unclear, new findings point to the interaction of genetic and environmental factors. ${ }^{3}$ Neuroimaging

Received: May 14, 2021 Revised: September 2, 2021

Accepted: September 13, 2021

$\triangle$ Correspondence: İbrahim Gündoğmuş, MD

Department of Psychiatry, Kırıkkale Yüksek İhtisas Hospital, Bağlarbaşı, Ahmet Ay Caddesi, 71300 Merkez, Kırıkkale, Turkey Tel: +905455870575, E-mail: dribrahim06@gmail.com

(a) This is an Open Access article distributed under the terms of the Creative Commons Attribution Non-Commercial License (https://creativecommons.org/licenses/bync/4.0) which permits unrestricted non-commercial use, distribution, and reproduction in any medium, provided the original work is properly cited. studies have shown that there are structural and functional brain differences between individuals with and without ADHD, ${ }^{4,5}$ Analyzes found global reductions in total brain volume, particularly in the prefrontal cortex (PFC), basal ganglia, and cerebellum. ${ }^{6}$ In addition, it has been reported that cortical thickness decreases in people with $\mathrm{ADHD}$, most prominently in the prefrontal and precentral regions. ${ }^{78}$ Besides, it has been shown that individuals with ADHD have maturation delay in cortical development. $^{9}$

The retina is considered to be part of the central nervous system as it originates from the diencephalon during embryonic development. ${ }^{10}$ Optical coherence tomography (OCT) is a noninvasive imaging technique that provides very high-resolution cross-sectional images of the retina and optic disc. ${ }^{11}$ It is used to measure changes in the retinal nerve fiber layer (RNFL), macular thickness (MT) and macular volume (MV) in the diagnosis and follow-up of ophthalmologic disorders, including 
glaucoma and macular diseases. In studies conducted with OCT and RNFL in the psychiatric field; thinner RNFL and MT have been reported in many psychiatric disorders, including schizophrenia. ${ }^{12,13}$ In addition to that, there are also studies conducted with children diagnosed with bipolar disorder, ${ }^{12}$ autism spectrum disorder, ${ }^{14}$ depressive disorder, ${ }^{15}$ and ADHD. ${ }^{16,17}$ However, as far as we know, there is no study investigating RNFL thickness in adults with ADHD.

Executive functions have been found to be associated with the PFC and its connections. ${ }^{18}$ Today, it has been clearly demonstrated that $\mathrm{ADHD}$ is a psychopathology that develops on the basis of dysfunction of the prefrontal cortical areas. ${ }^{19}$ Studies show that individuals with ADHD have poor performance in executive function tests. ${ }^{20,21}$ In neuropsychological tests performed on children with ADHD, impairment in functions such as wakefulness, arrest of motor response, planning, organization, learning, and recall of verbal information, which are known as executive functions, are reported..$^{22}$ In a study conducted with 1,485 healthy volunteers in which the relationship of RNFL thickness with cognitive functions was evaluated, it was shown that RNFL was significantly thicker in people with better neuropsychological test scores. ${ }^{23}$ Although studies evaluating retinal layers in mental diseases have been conducted in many different patient groups recently, the relationship between OCT findings and cognitive functions in adult ADHD individuals was not examined in any of these studies.

In the light of all this information, in this study, it is planned to compare RNFL thickness in adult ADHD individuals with controls and to examine the relationship between RNFL thickness and symptom severity and performance level in executive function tests.

\section{METHODS}

\section{Study sample}

Among the patients applied to the Health Sciences University Gülhane Medical Faculty Mental Health and Diseases Clinic, 38 volunteer patients diagnosed with ADHD according to DSM- 5 criteria and 30 healthy age-gender compatible volunteer between $18^{-55}$ years old are included in this study. The criteria for inclusion in the study is determined as, being between 18-55 years old, having at least primary education, being diagnosed with ADHD according to DSM-5, not having a comorbid diagnosis according to DSM-5, not using psychiatric medication for the last year, not having alcohol and substance use disorder, not having a risky neurological disease such as epilepsy, head trauma, encephalitis, meningitis, organic brain disease and cerebrovascular pathologies, not having neurodegenerative disease (Alzheimer, Parkinson, etc.) that may affect the clinical situation and not having any known disease that may affect RNFL thickness.

In order to clarify the diagnosis and determine the comorbidities, The Structured Clinical Interview for DSM-IV Axis I Disorders (SCID-I) and Diagnostic Interview for ADHD in Adults (DIVA 2.0) were applied to all participants by experienced psychiatrists. According to the evaluations, patients with psychiatric comorbidities were excluded from the study. Adult ADHD self-report scale (ASRS) was used for ADHD disease severity. Executive functions were evaluated with number range test, verbal fluency test, stroop test, trail making test. RNFL thickness of all participants was evaluated by OCT.

The study was approved by the Health Sciences University Non-Invasive Research Ethics Committee with the project/decision number 19/243 dated 25.06.2019. All stages of the study were carried out in accordance with the Helsinki Declaration rules.

\section{Data collection tools}

\section{Sociodemographic Data Form}

This form was developed by the researchers in accordance with the literature and the aims of the study, along with data about age, gender, marital status, educational status of the participants, such data like duration of illness, age of onset, family history, medical illness history, psychiatric medication and non-psychiatric drug use, suicide attempt history were also recorded.

\section{Adult ADHD self-report scale (ASRS-v1.1)}

The validity and reliability study of the Turkish version of the ASRS, which can help diagnose ADHD in adults, was conducted by Doğan et al. ${ }^{24}$ It is one of the scales developed by the World Health Organization (WHO) to screen mental disorders. ${ }^{25}$ The scale has two subscales namely "attention deficit" and "hyperactivity/impulsivity." The questions are aimed at determining how often each symptom has occurred in the last six months.

\section{Diagnostic interview form for ADHD in adults (DIVA 2.0)}

It is a structured $\mathrm{ADHD}$ diagnostic interview for adults based on DSM-IV ADHD diagnostic criteria. It enables the evaluation of 18 criteria for ADHD determined in childhood and adulthood with concrete and realistic examples. To evaluate the deterioration in two or more areas of daily life; It deals with five main areas: work and education, relationships and family life, social contacts, leisure and hobbies, self-confidence and self-perception. It was introduced into Turkish in May 2013. ${ }^{26}$ 


\section{Stroop Test}

Stroop Test is a neuropsychological test showing frontal lobe activities. ${ }^{27}$ This test reveals the ability to change the perception in line with changing demands and under a 'disruptive effect', and the ability to suppress a habitual behavior pattern and perform an unusual behavior. ${ }^{28,29}$

\section{Digit Span Test}

Digit span test, which is a subscale of the Wechlers Adult Intelligence Scale-Revised (WAIS-R) battery, is the most commonly used attention/short-term memory test worldwide. ${ }^{30} \mathrm{It}$ is applied in forward and backward, with an increasing number of numbers being sequenced, in two parts, a straight and inverted number sequence. Straight number counting is useful for simple evaluation. It is based on the ability of the person to keep in mind and repeat the said mixed numbers in the same order correctly, up to how many numbers. Inverse number counting, on the other hand, is useful for evaluating complex attention as it requires mental tracing. It is based on the ability of the person to repeat the said complex numbers without breaking the order from the end to the beginning. ${ }^{31}$

\section{Trail Making Test}

Trail Making Tests are a test that measures executive functions such as working memory, complex attention, planning and set changing. It consists of two parts, A and B. Part A of the tracing test, which is an executive function test, evaluates the processing speed based on visual scanning capability, and part B evaluates the ability to change the setup between stimulus sets and follow the sequencing. ${ }^{32}$

\section{Verbal Fluency Test}

Verbal Fluency Test consists of word fluency test and category naming sections. Controlled Word Fluency Test (Phonemic Word Fluency Test) evaluates verbal fluency, which is one of the important executive functions of the prefrontal cortex. In practice, the person is asked to derive as many words as possible, starting with the specified letter within one minute, and avoid repetition. It is frequently used in cases of attention deficit in which executive functions such as attention capacity, ability to sustain behavior, and susceptibility are evaluated. ${ }^{33}$ In this research, phonemic word fluency test was conducted.

\section{Optical coherence tomography}

For the measurement of OCT, the patient and the OCT technician are asked to sit on each other, lean the patient's chin on the device and fix his eye to the light directed by the technician. After fixation, measurements are taken from the right and left eyes. Thanks to this measurement, all layers of the retina-vitreous interface and the macula region up to the retinal pigment epithelium is evaluated in detail.

Peripapillary RNFL thickness measurements were performed with Heidelberg Spectralis OCT (software version 6.8, Heidelberg Engineering, Heidelberg, Germany) device without dilating the pupil. Circular scans with 360 degrees $3.4 \mathrm{~mm}$ diameter centered on the optical disc were performed. The imaged peripapillary RNFL was automatically divided into superotemporal, temporal, inferotemporal, inferonasal, nasal and superonasal segments using Heidelberg Eye Explorer software (version 1.10.0.0; Heidelberg Engineering). Global RNFL thickness and RNFL thickness in these segments were calculated automatically by the device.

\section{Statistical analysis}

SPSS 22 (IBM Corp., Armonk, NY, USA) package program for Windows was used in the statistical analysis of the data. Descriptive analysis methods were applied first after the sociode-

Table 1. Comparison of the sociodemographic data of the groups

\begin{tabular}{|c|c|c|c|c|}
\hline \multirow{2}{*}{ Variable } & \multicolumn{2}{|c|}{ Groups } & \multirow{2}{*}{$t / \chi^{2}$} & \multirow[b]{2}{*}{$\mathrm{p}$} \\
\hline & ADHD & Control & & \\
\hline Age (year) & $23.21 \pm 6.87$ & $23.63 \pm 3.85$ & $\mathrm{t}=0.321$ & 0.750 \\
\hline Gender & & & $\chi^{2}=0.272$ & 0.602 \\
\hline Woman & $15(39.5)$ & $10(33.3)$ & & \\
\hline Man & $23(60.5)$ & $20(66.7)$ & & \\
\hline Marital status & & & $\chi^{2}=0.550$ & 0.458 \\
\hline İn a relationship & $4(10.5)$ & $5(16.7)$ & & \\
\hline Single & $34(89.5)$ & $25(83.3)$ & & \\
\hline Education status & & & $\chi^{2}=13.918$ & $<0.001$ \\
\hline High school & $14(36.8)$ & $0(0)$ & & \\
\hline University & $24(63.2)$ & $30(100)$ & & \\
\hline Employment status & & & $\chi^{2}=6.317$ & 0.012 \\
\hline Working & $6(15.8)$ & $13(43.3)$ & & \\
\hline Unemployed & $32(84.2)$ & $17(56.7)$ & & \\
\hline Smoking & & & $\chi^{2}=2.766$ & 0.096 \\
\hline Yes & $8(21.1)$ & $30(78.9)$ & & \\
\hline No & $2(6.7)$ & $28(93.3)$ & & \\
\hline Family history & & & $\chi^{2}=3.676$ & 0.055 \\
\hline Yes & $7(18.4)$ & $1(3.3)$ & & \\
\hline No & $31(81.6)$ & $29(96.7)$ & & \\
\hline \multicolumn{2}{|c|}{ Family psychiatric history } & & $\chi^{2}=0.716$ & 0.398 \\
\hline Yes & $11(28.9)$ & $6(20.0)$ & & \\
\hline No & $27(71.1)$ & $24(80.0)$ & & \\
\hline Physical illness & & & $\chi^{2}=2.478$ & 0.115 \\
\hline Yes & $3(7.9)$ & 0 & & \\
\hline No & $35(92.1)$ & $30(100)$ & & \\
\hline
\end{tabular}

Data are presented as the mean \pm standard deviation or $\mathrm{N}$ (\%). ADHD, attention deficit hyperactivity disorder 
mographic, clinical and RNFL values of the participants were recorded in the appropriate data set. Descriptive statistics were expressed as numbers and percentages for categorical variables and as mean \pm standard deviation for numerical variables. Pearson chi-square test was used for statistical comparison of categorical variables of ADHD and control group. In comparing the numerical data between the two groups, it was first examined whether it met the necessary assumptions for parametric tests. For those who met the assumptions in the parametric tests, the Mann Withney U test was used for those who did not meet the Student t-test. To examine the relationship between two numerical variables, Pearson correlation analysis was performed for parametric tests if they met the assumptions, and Spearman correlation analysis was performed if they did not. In all statistical analyzes, $\mathrm{p} \leq 0.05$ was considered statistically significant.

\section{RESULTS}

The comparison of the sociodemographic data of the ADHD group and the health control group is presented in Table 1. A statistical difference was found between the education and employment status between the two groups ( $\mathrm{p}<0.001,<0.001$ and 0.012 , respectively). However, there was no statistically significant difference between the two groups in terms of age, gender, marital status, smoking and family characteristics ( $p>$ 0.05). A statistically significant difference was found between the two groups in the ASRS attention deficit subscale, hyperactivity/impulsivity subscale and total scores of the cases $(\mathrm{p}<$ 0.001). A statistically significant difference was found between the Stroop Test, Digit Span Test, Trail Making Test and Verbal Fluency Test subscale scores between the two groups $(\mathrm{p}<0.05)$ (Table 2).

When the RNFL values of the cases were compared between the two groups, a statistically significant difference was found between the right mean, right temporal, right temporal inferior, left mean, left nasal and left nasal inferior quadrant values $(\mathrm{p}<0.05)$. However, no statistical difference was found between right temporal superior, right nasal superior, right nasal, right nasal inferior, left temporal, left temporal superior, left temporal inferior and left nasal superior quadrant values ( $\mathrm{p}>$ 0.05) (Table 3).

The relationship between RNFL thickness and symptom severity and executive functions of ADHD cases is examined in Tables 4 and 5. Accordingly, there was no statistically signifi-

Table 2. Comparison of ASRS scores of the subjects

\begin{tabular}{|c|c|c|c|c|}
\hline \multirow{2}{*}{ Variable } & \multicolumn{2}{|c|}{ Groups } & \multirow{2}{*}{$\mathrm{t} / \mathrm{Z}$} & \multirow{2}{*}{$\mathrm{p}$} \\
\hline & ADHD & Control & & \\
\hline \multicolumn{5}{|l|}{ ASRS } \\
\hline Attention deficit & $14.28 \pm 3.20$ & $6.86 \pm 3.41$ & $\mathrm{t}=9.219$ & $<0.001$ \\
\hline Hyperactivity/impulsivity & $28.10 \pm 7.68$ & $12.23 \pm 4.99$ & $\mathrm{t}=9.785$ & $<0.001$ \\
\hline Total score & $42.39 \pm 10.16$ & $19.10 \pm 7.32$ & $\mathrm{t}=10.568$ & $<0.001$ \\
\hline \multicolumn{5}{|l|}{ Stroop Test } \\
\hline Stroop 1 & $11.35 \pm 3.85$ & $8.84 \pm 1.74$ & $Z=-3.471$ & 0.001 \\
\hline Stroop 2 & $12.18 \pm 5.30$ & $8.33 \pm 0.97$ & $Z=-4.836$ & $<0.001$ \\
\hline Stroop 3 & $14.48 \pm 4.54$ & $9.90 \pm 1.34$ & $\mathrm{t}=5.775$ & $<0.001$ \\
\hline Stroop 4 & $18.11 \pm 6.27$ & $11.64 \pm 1.50$ & $\mathrm{t}=6.145$ & $<0.001$ \\
\hline Stroop 5 & $31.34 \pm 15.02$ & $16.78 \pm 3.37$ & $Z=-5.175$ & $<0.001$ \\
\hline \multicolumn{5}{|l|}{ Digit Sequence Test } \\
\hline Straight number sequence & $3.57 \pm 1.17$ & $5.46 \pm 0.68$ & $t=-8.283$ & $<0.001$ \\
\hline Inverted number sequence & $3.05 \pm 1.03$ & $4.90 \pm 0.84$ & $t=-7.894$ & $<0.001$ \\
\hline \multicolumn{5}{|l|}{ Trail Making Test } \\
\hline Part A & $31.62 \pm 11.22$ & $18.88 \pm 51.79$ & $Z=6.046$ & $<0.001$ \\
\hline Part B & $72.85 \pm 29.14$ & $38.65 \pm 8.61$ & $Z=6.864$ & $<0.001$ \\
\hline \multicolumn{5}{|l|}{ Verbal Fluency Test } \\
\hline Verbal Fluency K & $13.31 \pm 4.05$ & $20.76 \pm 4.31$ & $t=-7.316$ & $<0.001$ \\
\hline Verbal Fluency A & $10.00 \pm 3.64$ & $16.66 \pm 3.48$ & $t=-0.630$ & $<0.001$ \\
\hline Verbal Fluency S & $11.18 \pm 3.42$ & $18.06 \pm 3.02$ & $t=-8.656$ & $<0.001$ \\
\hline
\end{tabular}

Data are presented as mean \pm standard deviation. ASRS, adult attention hyperactivity disorder self-report scale; ADHD, attention deficit hyperactivity disorder 
Table 3. Comparison of retinal nerve fiber layer thickness between groups

\begin{tabular}{|c|c|c|c|c|c|}
\hline \multirow{2}{*}{ Variable } & \multicolumn{2}{|c|}{ Groups } & \multirow{2}{*}{$\mathrm{t}$} & \multirow{2}{*}{$\mathrm{df}$} & \multirow{2}{*}{$\mathrm{p}$} \\
\hline & $\mathrm{ADHD}$ & Control & & & \\
\hline \multicolumn{6}{|c|}{ Right retinal nerve fiber layer thickness } \\
\hline Average & $97.71 \pm 12.00$ & $103.40 \pm 9.91$ & -2.092 & 66 & 0.040 \\
\hline Temporal & $73.97 \pm 14.14$ & $84.43 \pm 13.35$ & -3.103 & 66 & 0.003 \\
\hline Temporal superior & $138.60 \pm 22.53$ & $142.90 \pm 15.36$ & -0.932 & 66 & 0.355 \\
\hline Nasal superior & $102.00 \pm 23.28$ & $107.73 \pm 16.10$ & -1.198 & 64.8 & 0.255 \\
\hline Nasal & $74.47 \pm 18.37$ & $75.86 \pm 13.24$ & -0.363 & 65.5 & 0.718 \\
\hline Nasal inferior & $109.00 \pm 29.96$ & $106.40 \pm 17.38$ & 0.448 & 61.1 & 0.656 \\
\hline Temporal inferior & $130.63 \pm 26.64$ & $149.93 \pm 21.38$ & -3.229 & 66 & 0.002 \\
\hline \multicolumn{6}{|c|}{ Left retinal nerve fiber layer thickness } \\
\hline Average & $96.10 \pm 11.85$ & $102.20 \pm 11.25$ & -2.153 & 66 & 0.035 \\
\hline Temporal & $67.18 \pm 16.80$ & $70.20 \pm 13.81$ & -0.794 & 66 & 0.430 \\
\hline Temporal superior & $108.97 \pm 23.26$ & $115.16 \pm 21.62$ & -1.124 & 66 & 0.265 \\
\hline Nasal superior & $135.57 \pm 23.43$ & $144.53 \pm 21.07$ & -1.635 & 66 & 0.107 \\
\hline Nasal & $72.39 \pm 12.05$ & $83.36 \pm 12.75$ & -3.632 & 66 & 0.001 \\
\hline Nasal inferior & $137.42 \pm 23.66$ & $150.13 \pm 17.24$ & -2.468 & 66 & 0.016 \\
\hline Temporal inferior & $107.84 \pm 24.05$ & $104.30 \pm 17.43$ & 0.703 & 65.5 & 0.484 \\
\hline
\end{tabular}

Data are presented as mean \pm standard deviation. ADHD, attention deficit hyperactivity disorder

cant correlation between the mean RNFL thickness values of the right and left eyes, symptom severity and executive functions $(\mathrm{p}>0.05)$.

\section{DISCUSSION}

Examination of retinal layers with OCT in psychiatric diseases has been a topic that has come to the fore in recent years, and there are limited studies conducted with ADHD patients in the literature. As far as we know, our study is important because it is the first study investigating the relationship between RNFL thickness and ADHD severity and executive functions in adult ADHD. In the study, RNFL thicknesses of adult ADHD patients and healthy volunteers were compared and the relationship of these parameters with symptom severity and executive functions was evaluated.

According to the findings obtained from the OCT measurement in our study, the mean RNFL thickness in the ADHD group was significantly thinner in the right and left eyes compared to the control group. In addition, right temporal, right temporal inferior, left nasal, left nasal inferior quadrant thicknesses of the RNFL subgroups were found to be significantly thinner in the ADHD group compared to the control group.

While our findings are similar to the study conducted by Herguner et al. ${ }^{16}$ one of the studies that previously examined the relationship between ADHD and RNFL, the results of the study conducted by Bodur et al. ${ }^{17}$ do not coincide with the re- sults of our study. In a recent study, children with ADHD who did not receive treatment, children with ADHD who were followed up under regular methylphenidate treatment for at least 3 months, and the control group were evaluated in terms of OCT parameters, and no significant difference was found between the groups in terms of mean RNFL thickness. ${ }^{34}$ When the result obtained in our study is evaluated within the literature information, it seems to support the hypothesis that ADHD is related to the neurodegenerative process. However, further studies are needed to be conducted to explain these results better.

The results of studies conducted with psychiatric diseases other than ADHD also seem to conflict with each other. Although the duration and severity of the disease can be measured in schizophrenia and bipolar disorder, it is often not possible to evaluate this in ADHD. Because ADHD; due to the lack of precise scales to diagnose, the scales being self-report, and frequently accompanying comorbid conditions, it often presents with delay and misdiagnosis. In addition, these findings suggest that there is no such serious neurodegeneration in ADHD as in schizophrenia. This may be an explanation for the reason why the results of our study seem to partially contradict the literature. ${ }^{16}$ The reason for this may be the small sample size. It will be more beneficial to repeat similar studies with many samples.

Recent studies have noted that the visual pathway is an ideal structure for research in the field of neurodegeneration. ${ }^{10,35,36}$ In vivo imaging of the retina is promising for early evaluation 
Table 4. Relationship between right retinal nerve fiber layer thickness and ASRS and performance level in executive function tests

\begin{tabular}{llllllll}
\hline \multicolumn{8}{c}{ Right retinal nerve fiber layer thickness } \\
\cline { 2 - 7 } & $\mathrm{T}$ & TS & NS & N & NI & TI \\
\hline
\end{tabular}

ASRS

Attention deficit

$\begin{array}{llllllll}\mathrm{r} & 0.314 & 0.174 & 0.255 & 0.260 & 0.123 & 0.237 & 0.204 \\ \mathrm{p} & 0.055 & 0.295 & 0.122 & 0.115 & 0.462 & 0.151 & 0.220\end{array}$

Hyperactivity/impulsivity

$\begin{array}{cccccccc}\mathrm{r} & 0.238 & 0.193 & 0.232 & 0.165 & 0.024 & 0.151 & 0.110 \\ \mathrm{p} & 0.149 & 0.247 & 0.161 & 0.324 & 0.886 & 0.367 & 0.510 \\ \text { Total } & & & & & & & \\ \mathrm{r} & 0.279 & 0.201 & 0.256 & 0.206 & 0.057 & 0.189 & 0.148 \\ \mathrm{p} & 0.089 & 0.227 & 0.121 & 0.214 & 0.734 & 0.256 & 0.376\end{array}$

Stroop Test

Stroop Test 1

$\begin{array}{llllllll}\text { r } & 0.286 & -0.201 & 0.099 & 0.367 & 0.284 & 0.463 & -0.087\end{array}$

$\begin{array}{llllllll}\text { p } & 0.081 & 0.225 & 0.553 & 0.023^{*} & 0.084 & 0.003 * * & 0.603\end{array}$

Stroop Test 2

$\begin{array}{llllllll}\mathrm{r} & 0.186 & -0.261 & 0.038 & 0.339 & 0.174 & 0.444 & -0.153 \\ \mathrm{p} & 0.263 & 0.113 & 0.820 & 0.037^{*} & 0.298 & 0.005^{* *} & 0.359\end{array}$

Stroop Test 3

$\begin{array}{llllllll}\mathrm{r} & 0.232 & -0.148 & -0.009 & 0.248 & 0.130 & 0.391 & -0.071\end{array}$

$\begin{array}{llllllll}\mathrm{p} & 0.161 & 0.377 & 0.959 & 0.133 & 0.437 & 0.015^{*} & 0.673\end{array}$

Stroop Test 4

$\begin{array}{llllllll}\text { r } & 0.155 & -0.229 & -0.036 & 0.217 & 0.215 & 0.344 & -0.099\end{array}$

$\begin{array}{llllllll}\text { p } & 0.353 & 0.167 & 0.832 & 0.191 & 0.195 & 0.034^{*} & 0.555\end{array}$

Stroop Test 5

$\begin{array}{llllllll}\mathrm{r} & 0.138 & -0.141 & 0.004 & 0.268 & 0.161 & 0.309 & -0.137\end{array}$

$\begin{array}{llllllll}\text { p } & 0.409 & 0.398 & 0.981 & 0.103 & 0.335 & 0.059 & 0.413\end{array}$

Digit Sequence Test

Straight number sequence

$\begin{array}{lrrrrrrr}\mathrm{r} & -0.097 & 0.100 & -0.082 & -0.224 & -0.182 & -0.107 & 0.000 \\ \mathrm{p} & 0.563 & 0.550 & 0.625 & 0.177 & 0.275 & 0.521 & 1.000\end{array}$

Inverted number sequence

$\begin{array}{lrrrrrrr}\mathrm{r} & -0.016 & 0.131 & 0.129 & -0.130 & -0.239 & -0.184 & 0.052 \\ \mathrm{p} & 0.924 & 0.434 & 0.440 & 0.438 & 0.148 & 0.268 & 0.759\end{array}$

Trail Making Test

Part A

$\begin{array}{llllllll}\text { r } & 0.190 & -0.321 & 0.143 & 0.327 & 0.259 & 0.367 & -0.211\end{array}$

$\begin{array}{llllllll}\text { p } & 0.252 & 0.050^{*} & 0.391 & 0.045^{*} & 0.116 & 0.023 & 0.204\end{array}$

Part B

$\begin{array}{llllllll}\mathrm{r} & 0.016 & -0.314 & -0.091 & 0.337 & 0.174 & 0.241 & -0.210\end{array}$

$\begin{array}{llllllll}\text { p } & 0.925 & 0.055 & 0.587 & 0.039 * & 0.298 & 0.145 & 0.206\end{array}$
Table 4. Relationship between right retinal nerve fiber layer thickness and ASRS and performance level in executive function tests (continued)

\begin{tabular}{ccccccccc}
\hline \multicolumn{8}{c}{ Right retinal nerve fiber layer thickness } \\
\cline { 2 - 8 } & $\mathrm{A}$ & $\mathrm{T}$ & $\mathrm{TS}$ & $\mathrm{NS}$ & $\mathrm{N}$ & $\mathrm{NI}$ & $\mathrm{TI}$ \\
\hline \multicolumn{1}{l}{ Verbal Fluency Test } \\
Verbal Fluency K \\
r & 0.017 & -0.071 & 0.171 & 0.042 & 0.055 & -0.221 & -0.159 \\
$\mathrm{p}$ & 0.917 & 0.674 & 0.306 & 0.801 & 0.743 & 0.183 & 0.342 \\
Verbal Fluency A & & & & & \\
r & 0.088 & 0.006 & 0.236 & 0.083 & 0.033 & -0.077 & -0.169 \\
$\mathrm{p}$ & 0.598 & 0.970 & 0.153 & 0.620 & 0.842 & 0.645 & 0.310 \\
Verbal Fluency S & & & & & \\
r & -0.069 & 0.276 & 0.162 & -0.110 & -0.161 & -0.300 & 0.018 \\
$\mathrm{p}$ & 0.680 & 0.094 & 0.330 & 0.512 & 0.333 & 0.068 & 0.913 \\
\hline
\end{tabular}

${ }^{*} \mathrm{p}<0.05 ;{ }^{* *} \mathrm{p}<0.01$. ASRS, adult attention hyperactivity disorder self-report scale

of degenerative processes in the CNS. ${ }^{37}$ In particular, RNFL containing the axons of retinal ganglion cells may be considered unique in some respects. The axons are unmyelinated until they unite as optic nerves, and from an embryological point of view, these nerve fibers can be considered an extension of the brain. ${ }^{38}$ This situation turns the retina into a "window to the brain." OCT provides an advantage for fast and easy application and imaging of retinal layers with high reproducibility. ${ }^{39}$ These features may allow complementary diagnostic and prognostic information in different psychiatric disorders affecting the CNS. ${ }^{40}$

According to the findings obtained from our study, considering the ASRS total scores; there was no significant relationship between the increase in symptom severity and RNFL thickness. This finding is incompatible with the negative correlation between the symptom severity and RNFL thickness found by Herguner et al. ${ }^{16}$ The reason for this may be the small sample size. It will be more beneficial to repeat similar studies with many samples.

Studies on the relationship between OCT and cognitive functions generally focused on neurodegenerative diseases. The results obtained from these studies show that OCT findings in Alzheimer's and Multiple Sclerosis patients correlate with MRI findings and RNFL is associated with cognitive performance, especially memory functions. ${ }^{40-43}$ However, in a study conducted with 1,485 healthy volunteers in which the relationship between RNFL thickness and cognitive functions was evaluated, it was shown that RNFL was significantly thicker in people with better neuropsychological test scores. ${ }^{23}$ Although studies evaluating retinal layers in mental diseases have been conducted in many different patient groups in recent years, the relationship 
Table 5. Relationship between left retinal nerve fiber layer thickness and ASRS and performance level in executive function tests

\begin{tabular}{llllllll}
\hline \multicolumn{8}{c}{ Right retinal nerve fiber layer thickness } \\
\cline { 2 - 8 } & T & TS & NS & N & NI & TI \\
\hline
\end{tabular}

ASRS

Attention deficit

$\begin{array}{llllllll}\mathrm{r} & 0.274 & 0.097 & 0.244 & 0.156 & 0.278 & 0.309 & 0.177 \\ \mathrm{p} & 0.096 & 0.563 & 0.140 & 0.349 & 0.091 & 0.059 & 0.288\end{array}$

Hyperactivity/impulsivity

$\begin{array}{cccccccc}\mathrm{r} & 0.227 & 0.093 & 0.126 & 0.117 & 0.161 & 0.181 & 0.142 \\ \mathrm{p} & 0.171 & 0.581 & 0.450 & 0.486 & 0.334 & 0.276 & 0.397 \\ \text { Total } & & & & & & & \\ \mathrm{r} & 0.258 & 0.101 & 0.173 & 0.137 & 0.210 & 0.235 & 0.163 \\ \mathrm{p} & 0.118 & 0.548 & 0.300 & 0.410 & 0.207 & 0.156 & 0.328\end{array}$

Stroop Test

Stroop Test 1

$\begin{array}{llllllll}\mathrm{r} & 0.287 & 0.300 & 0.448 & 0.087 & -0.082 & 0.010 & 0.325\end{array}$

$\begin{array}{llllllll}\text { p } & 0.080 & 0.067 & 0.005^{* *} & 0.603 & 0.626 & 0.955 & 0.047\end{array}$

Stroop Test 2

$\begin{array}{llllllll}\mathrm{r} & 0.171 & 0.052 & 0.357 & 0.026 & -0.028 & -0.003 & 0.299\end{array}$

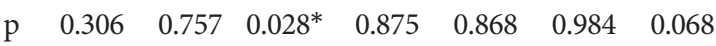

Stroop Test 3

$\begin{array}{llllllll}\mathrm{r} & 0.211 & 0.062 & 0.355 & 0.080 & 0.036 & -0.008 & 0.219 \\ \mathrm{p} & 0.203 & 0.712 & 0.029 & 0.631 & 0.830 & 0.961 & 0.188\end{array}$

Stroop Test 4

$\begin{array}{llllllll}\mathrm{r} & 0.142 & 0.213 & 0.349 & 0.019 & -0.109 & -0.062 & 0.249\end{array}$

$\begin{array}{llllllll}\mathrm{p} & 0.395 & 0.198 & 0.032 * & 0.911 & 0.516 & 0.713 & 0.132\end{array}$

Stroop Test 5

$\begin{array}{llllllll}r & 0.173 & 0.126 & 0.345 & 0.003 & -0.098 & -0.060 & 0.214\end{array}$

$\begin{array}{llllllll}\text { p } & 0.299 & 0.449 & 0.034^{*} & 0.984 & 0.558 & 0.722 & 0.196\end{array}$

Digit Sequence Test

Straight number sequence

$\begin{array}{llllllll}r & -0.154 & -0.074 & -0.219 & -0.059 & 0.113 & 0.006 & -0.001\end{array}$

$\begin{array}{llllllll}\text { p } & 0.357 & 0.659 & 0.187 & 0.727 & 0.500 & 0.974 & 0.998\end{array}$

Inverted number sequence

$\begin{array}{lrrrrrrr}\mathrm{r} & -0.058 & -0.097 & -0.291 & 0.052 & 0.126 & 0.013 & 0.048 \\ \mathrm{p} & 0.731 & 0.564 & 0.076 & 0.756 & 0.452 & 0.937 & 0.775\end{array}$

Trail Making Test

Part A

$\begin{array}{llllllll}\mathrm{r} & 0.225 & 0.208 & 0.408 & 0.117 & -0.082 & 0.003 & 0.169\end{array}$

$\begin{array}{llllllll}\mathrm{p} & 0.175 & 0.211 & 0.011^{*} & 0.484 & 0.626 & 0.985 & 0.310\end{array}$

Part B

$\begin{array}{llllllll}r & 0.096 & 0.057 & 0.353 & -0.106 & -0.165 & -0.099 & 0.212\end{array}$

$\begin{array}{llllllll}\mathrm{p} & 0.565 & 0.736 & 0.030^{*} & 0.527 & 0.322 & 0.554 & 0.202\end{array}$
Table 5. Relationship between left retinal nerve fiber layer thickness and ASRS and performance level in executive function tests (continued)

\begin{tabular}{|c|c|c|c|c|c|c|c|}
\hline & \multicolumn{7}{|c|}{ Right retinal nerve fiber layer thickness } \\
\hline & $\mathrm{A}$ & $\mathrm{T}$ & TS & NS & $\mathrm{N}$ & $\mathrm{NI}$ & TI \\
\hline \multicolumn{8}{|c|}{ Verbal Fluency Test } \\
\hline \multicolumn{8}{|c|}{ Verbal Fluency K } \\
\hline $\mathrm{r}$ & 0.101 & 0.109 & -0.048 & 0.080 & 0.001 & -0.171 & -0.031 \\
\hline $\mathrm{p}$ & 0.546 & 0.513 & 0.775 & 0.633 & 0.994 & 0.305 & 0.854 \\
\hline \multicolumn{8}{|c|}{ Verbal Fluency A } \\
\hline $\mathrm{r}$ & 0.152 & 0.173 & -0.034 & 0.159 & 0.061 & -0.186 & 0.069 \\
\hline $\mathrm{p}$ & 0.363 & 0.299 & 0.839 & 0.339 & 0.714 & 0.264 & 0.679 \\
\hline \multicolumn{8}{|c|}{ Verbal Fluency S } \\
\hline $\mathrm{r}$ & -0.048 & -0.033 & -0.255 & 0.072 & 0.152 & -0.052 & -0.003 \\
\hline $\mathrm{p}$ & 0.773 & 0.846 & 0.123 & 0.666 & 0.362 & 0.756 & 0.988 \\
\hline
\end{tabular}

${ }^{*} \mathrm{p}<0.05 ;{ }^{* *} \mathrm{p}<0.01$. ASRS, adult attention hyperactivity disorder self-report scale

between OCT findings and cognitive functions in adults with ADHD has not been examined in any of these studies. In our study, no statistically significant relationship was found between the mean RNFL thickness values of the right and left eyes and the level of performance in executive functions in the ADHD group. Although we think that especially the small sample size is the cause of this result, our study is a guide for the future in terms of being the first study conducted with ADHD. In addition, conducting studies enriched with other neuropsychological tests in larger groups will contribute more to this issue.

\section{Limitations}

The small sample size and insufficient literature are among our main limitations in our study. Self-report scales used for adult $\mathrm{ADHD}$ diagnosis can also be misleading. Besides, the fact that most of our patients are at a young age may not reflect the generality. As another factor, the fact that the research was conducted in a relatively narrow area and single center in the Central Anatolia Region is another limiting factor. Lack of sufficient studies in the literature examining the relationship between OCT findings and cognitive functions in adults with ADHD makes it difficult to interpret the results. New studies with larger samples are needed to understand the relationship between cognitive functions and OCT parameters in individuals with ADHD.

\section{Conclusion}

According to the findings obtained from the OCT measurement in our study, the mean RNFL thickness in the ADHD group was found to be significantly thinner in the right and left eyes compared to the control group. This finding seems 
to be compatible with the literature. There was no statistically significant relationship between symptom severity and RNFL thickness values in the ADHD group. Also, no significant relationship was found between RNFL thickness values and performance levels in executive function tests. Although we think that especially the small sample size causes this result; As it is the first study conducted with ADHD regarding the relationship between OCT and executive functions, our study is guiding for the future and it is thought that it will be useful to repeat it with studies with larger samples.

\section{Availability of Data and Material}

The datasets generated or analyzed during the study are available from the corresponding author on reasonable request.

\section{Conflicts of Interest}

The authors have no potential conflicts of interest to disclose.

\section{Author Contributions}

Conceptualization: Derya Kaymak, İbrahim Gündoğmuş, Mihriban Dalkıran, Özcan Uzun. Data curation: Derya Kaymak, Murat Küçükevcilioğlu, Özcan Uzun. Formal analysis: İbrahim Gündoğmuş, Özcan Uzun. Funding acquisition: Derya Kaymak, Özcan Uzun. Investigation: Derya Kaymak, İbrahim Gündoğmuş, Murat Küçükevcilioğlu, Özcan Uzun. Methodology: Derya Kaymak, İbrahim Gündoğmuş, Mihriban Dalkıran. Project administration: Derya Kaymak, Özcan Uzun. Resources: Derya Kaymak, Murat Küçükevcilioğlu. Software: Derya Kaymak, İbrahim Gündoğmuş, Murat Küçükevcilioğlu. Supervision: Derya Kaymak, İbrahim Gündoğmuş, Özcan Uzun. Validation: Derya Kaymak, Mihriban Dalkıran, Özcan Uzun. Visualization: Derya Kaymak, İbrahim Gündoğmuş. Writing_original draft: Derya Kaymak, İbrahim Gündoğmuş. Writing_review \& editing: all authors.

\section{ORCID iDs}

Derya Kaymak

İbrahim Gündoğmuş

Mihriban Dalkıran

Murat Küçükevcilioğlu

Özcan Uzun

https://orcid.org/0000-0002-1168-1417

https://orcid.org/0000-0002-1921-1495

https://orcid.org/0000-0003-2964-454X

https://orcid.org/0000-0001-7776-2183

https://orcid.org/0000-0002-4244-6911

\section{Funding Statement}

None

\section{REFERENCES}

1. American Psychiatric Association. Diagnostic and Statistical Manual of Mental Disorders, 5th Edition. Washington DC: American Psychiatric Publishing, Inc; 2013.

2. Barkley RA. History of ADHD. In: Barkley RA, Editor. Attention-Deficit Hyperactivity Disorder: a Handbook for Diagnosis and Treatment, Fourth Edition. New York: The Guilford Press, 2014, p.350.

3. Thapar A, Cooper M, Eyre O, Langley K. Practitioner Review: What have we learnt about the causes of ADHD? J Child Psychol Psychiatry 2013;54:3-16.

4. Friedman LA, Rapoport JL. Brain development in ADHD. Curr Opin Neurobiol 2015;30:106-111.

5. Valera EM, Faraone SV, Murray KE, Seidman LJ. Meta-Analysis of Structural Imaging Findings in Attention-Deficit/Hyperactivity Disorder. Biol Psychiatry 2007;61:1361-1369.

6. Friedman LA, Rapoport JL. Brain development in ADHD. Curr Opin Neurobiol 2015;30:106-111.
7. Cortese S, Castellanos FX. Neuroimaging of attention-deficit/hyperactivity disorder: current neuroscience-informed perspectives for clinicians. Curr Psychiatr Rep 2012;14:568-578.

8. Narr KL, Woods RP, Lin J, Kim J, Phillips OR, Del'Homme M, et al. Widespread cortical thinning is a robust anatomical marker for attention-deficit/hyperactivity disorder. J Am Acad Child Adolesc Psychiatry 2009;48:1014-1022.

9. Shaw P, Eckstrand K, Sharp W, Blumenthal J, Lerch JP, Greenstein D, et al. Attention-deficit/hyperactivity disorder is characterized by a delay in cortical maturation. Proc Natl Acad Sci U S A 2007;104:1964919654.

10. London A, Benhar I, Schwartz M. The retina as a window to the brainfrom eye research to CNS disorders. Nat Rev Neurol 2013;9:44-53.

11. Schönfeldt-Lecuona C, Kregel T, Schmidt A, Pinkhardt EH, Lauda F, Kassubek J, et al. From imaging the brain to imaging the retina: optical coherence tomography (OCT) in schizophrenia. Schizophr Bull 2016; 42:9-14.

12. Celik M, Kalenderoglu A, Sevgi Karadag A, Bekir Egilmez O, Han-Almis B, Şimşek A. Decreases in ganglion cell layer and inner plexiform layer volumes correlate better with disease severity in schizophrenia patients than retinal nerve fiber layer thickness: Findings from spectral optic coherence tomography. Eur Psychiatry 2016;32:9-15.

13. Yılmaz U, Küçük E, Ülgen A, Özköse A, Demircan S, Ulusoy DM, et al. Retinal nerve fiber layer and macular thickness measurement in patients with schizophrenia. Eur J Ophthalmol 2016;26:375-378.

14. Emberti Gialloreti L, Pardini M, Benassi F, Marciano S, Amore M, Mutolo MG, et al. Reduction in retinal nerve fiber layer thickness in young adults with autism spectrum disorders. J Autism Dev Disord 2014;44: 873-882.

15. Yıldız M, Alim S, Batmaz S, Demir S, Songur E, Ortak H, et al. Duration of the depressive episode is correlated with ganglion cell inner plexifrom layer and nasal retinal fiber layer thicknesses: Optical coherence tomography findings in major depression. Psychiatr Res Neuroimaging 2016;251:60-66.

16. Herguner A, Alpfidan I, Yar A, Erdoğan E, Metin Ö, Sakarya Y, et al. Retinal nerve fiber layer thickness in children with ADHD. J Atten Disord 2018;22:619-626.

17. Bodur Ş, Kara H, Açıkel B, Yapar E. Evaluation of the ganglion cell layer thickness in children with attention deficit hyperactivity disorder and comorbid oppositional defiant disorder. Turkish J Clin Psychiatry 2018;21:222-230.

18. Moore TL, Schettler SP, Killiany RJ, Rosene DL, Moss MB. Impairment in delayed nonmatching to sample following lesions of dorsal prefrontal cortex. Behav Neurosci 2012;126:772-780.

19. Shaw P, Eckstrand K, Sharp W, Blumenthal J, Lerch JP, Greenstein D, et al. Attention-deficit/hyperactivity disorder is characterized by a delay in cortical maturation. Proc Natl Acad Sci U S A 2007;104:1964919654.

20. Willcutt EG. The prevalence of DSM-IV attention-deficit/hyperactivity disorder: a meta-analytic review. Neurotherapeutics: the journal of the American Society for Experimental NeuroTherapeutics 2012;9:490499.

21. Froehlich T. What causes ADHD? Understanding what goes wrong and why. J Dev Behav Pediatr 2008;29:73.

22. Seidman LJ, Biederman J, Monuteaux MC, Valera E, Doyle AE, Faraone SV. Impact of gender and age on executive functioning: do girls and boys with and without attention deficit hyperactivity disorder differ neuropsychologically in preteen and teenage years? Dev Neuropsychol 2005;27:79-105.

23. van Koolwijk LME, Despriet DDG, Van Duijn CM, Oostra BA, van Swieten JC, de Koning I, et al. Association of cognitive functioning with retinal nerve fiber layer thickness. Invest Ophthalmol Vis Sci 2009;50: 4576-4580.

24. Doğan S, Oncu B, Varol-Saracoğlu G, Küçükgöncü S. Validity and reliability of the Turkish version of the Adult ADHD. Anadolu Psikiyatri 
Dergisi 2009;10:77-87.

25. Kessler RC, Adler L, Ames M, Demler O, Faraone S, Hiripi E, et al. The World Health Organization adult ADHD self-report scale (ASRS): A short screening scale for use in the general population. Psychol Med 2005;35:245-256.

26. Kooij JJS, Francken MH. Diagnostic Interview for ADHD (DIVA) in adults. Available at: www.divacentre.eu. Accessed July 24, 2019.

27. Stroop JR. Studies of interference in serial verbal reactions. J Exp Psychol 1935; 18:643-662.

28. Yalcın K, Karakaş S. Change with age of information processing metaoperations in children. Turk Psikiyatri Derg 2008;19:257-265.

29. Weintraub S. Neuropsychological Assessment of Mental State. In: Mesulam M, Editor. Principles of Behavioral and Cognitive Neurology, 2nd Edition. New York: Oxford University Press; 2000.

30. Sezgin N, Baştuğ G, Yargıcı Karağaç S, Yılmaz B. Turkish standardization of Wechsler Adult Intelligence Scale-Revised (WAIS-R): pilot study. J Ankara Univ Facult Lang History Geography 2014;1:451-480.

31. Reynolds CR, Powel J. Wechsler memory scale-revised. Arch Clin Neuropsychol 1988;3:397-403.

32. Turkeş N, Can H, Kurt M, Elmastaş Dikeç B. A study to determine the norms for the trail making test for the age range of 20-49 in Turkey. Turk Psikiyatri Dergisi 2015;26:189-196.

33. Jarratt K. Critical issues in neuropsychology: neuropsychological interpretations of objective psychological tests. Arch Clin Neuropsychol 2004;19:329-330.

34. Işik Ü, Kaygisiz M. Assessment of intraocular pressure, macular thickness, retinal nerve fiber layer, and ganglion cell layer thicknesses: ocular parameters and optical coherence tomography findings in attention- deficit/hyperactivity disorder. Braz J Psychiatry 2020;42:309-313.

35. Galetta KM, Calabresi PA, Frohman EM, Balcer LJ. Optical Coherence Tomography (OCT): imaging the visual pathway as a model for neurodegeneration. Neurotherapeutics 2011;8:117-132.

36. Simao LM. The contribution of optical coherence tomography in neurodegenerative diseases. Curr Opin Ophthalmol 2013;24:521-527.

37. Jindahra P, Hedges TR, Mendoza-Santiesteban CE, Plant GT. Optical coherence tomography of the retina: applications in neurology. Curr Opin Neurol 2010;23:16-23.

38. London A, Benhar I, Schwartz M. The retina as a window to the brainfrom eye research to CNS disorders. Nat Rev Neurol 2013;9:44-53.

39. Kim JS, Ishikawa H, Sung KR, Xu J, Wollstein G, Bilonick RA, et al. Retinal nerve fibre layer thickness measurement reproducibility improved with spectral domain optical coherence tomography. Br J Ophthalmol 2009;93:1057-1063.

40. Frohman EM, Fujimoto JG, Frohman TC, Calabresi PA, Cutter G, Balcer LJ. Optical coherence tomography: a window into the mechanisms of multiple sclerosis. Nat Clin Pract 2008;4:664-675.

41. Petzold A, de Boer JF, Schippling S, Vermersch P, Kardon R, Green A, et al. Optical coherence tomography in multiple sclerosis: a systematic review and meta-analysis. Lancet Neurol 2010;9:921-932.

42. Paquet C, Boissonnot M, Roger F, Dighiero P, Gil R, Hugon J. Abnormal retinal thickness in patients with mild cognitive impairment and Alzheimer's disease. Neurosci Lett 2007;420:97-99.

43. Shen Y, Liu L, Cheng Y, Feng W, Shi Z, Zhu Y, et al. Retinal nerve fiber layer thickness is associated with episodic memory deficit in mild cognitive impairment patients. Curr Alzheimer Res 2014;11:259-266. 